\title{
ANALISIS BULLWHIP EFFECT DENGAN MENGGUNAKAN METODE PERAMALAN PADA SUPPLY CHAIN DI DISTRIBUTOR PT. SEMEN TONASA (Studi Kasus: Distributor PT. Semen Tonasa)
}

\author{
W. Latuny \\ Program Studi Teknik Industri, Fakultas Teknik Universitas Pattimura, Ambon \\ Wisnu M. S. Picauly \\ Program Studi Teknik Industri, Fakultas Teknik Universitas Pattimura, Ambon
}

\begin{abstract}
ABSTRAK
Bullwhip effect merupakan fenomena pada supply chain, dimana adanya perbedaan jumlah permintaan konsumen ditiap periode baik itu semakin sedikit atau semakin banyak yang dapat berpengaruh pada seтиa tingkatan dalam supply chain. Hal itu juga yang dialami dari Sub Distributor PT. Padi Mas Prima yang mendistribusikan Produk Semen Tonasa pada tiap ritel di kota ambon yaitu ritel Aneka Guna,Ritel Benua dan Ritel Wayame Adapun tujuan penelitian ini Menganalisis Bullwhip Effect dengan metode peramalan dan meminimalisasi terjadinya bullwhip effect. Perhitungan bullwhip effect menggunakan pendekatan model Moving Average dan Single Exponential Smoothing yang akan dipilih berdasarkan Mean Absolute Deviation dan Tracking Signal Hasil dari penelitian model yang dipilih adalah model Single Exponential Smoothing diperoleh hasil dari peramalan selama 12 periode, dari hasil peramalan tersebut menunjukkan adanya penurunan nilai bullwhip effect pada Sub Distributor PT. Padi Mas Prima, yang sebelumnya 1.02 nilainya menjadi 0.18 dengan tingkat presentase penurunan sebesar $82.4 \%$, Ritel Aneka Guna yang nilainya 1.07 menjadi 0.71 dengan tingkat presentase penurunan sebesar 33.6\%, Ritel Benua yang nilainya 1.03 nilainya menurun menjadi 0.86 dengan tingkat presentase penurunan sebesar 16.5\%, dan Ritel Wayame yang sebelumnya 1.10 nilainya menurun menjadi 0.96 dengan tingkat presentase penurunan sebesar 12.7\%. Dimana nilai bullwhip effect > 1.01 dapat diartikan bahwa terjadi amplifikasi permintaan, sedangkan nilai bullwhip effect < 1.01 dapat diartikan bahawa permintaan masih stabil atau terjadi penghalusan pola permintaan usaha perbaikan dilakukan dengan melakukan pemesanan produk pada supplier dengan memperhatikan jumlah persediaan yang ada, menjaga arus informasi permintaan dan penjualan produk, serta menjaga lead time agar tetap stabil.
\end{abstract}

Kata kunci : Supply Chain, Bullwhip Effect,Moving Average,Single exponential Smoothing, Mean Absolute Deviation, tracking signal

\begin{abstract}
The bullwhip effect is a phenomenon in the supply chain, where there are differences in the number of consumer demand in each period whether it is less or more that can affect all levels of the supply chain. That was also experienced by PT. Padi Mas Prima distributes Semen Tonasa Products in every retail in Ambon city, namely Aneka Guna, Continent, and Wayame Retail. The purpose of this research is to Analyze the Bullwhip Effect with forecasting methods and minimize the occurrence of the bullwhip effect. Calculation of the bullwhip effect using the Moving Average and Single Exponential Smoothing model approach that will be selected based on Mean Absolute Deviation and Tracking Signal The results of the selected model research are the Single Exponential Smoothing model obtained from forecasting for 12 periods, the forecasting results indicate a decrease in the value of bullwhip effect on PT. Padi Mas Prima, which previously had 1.02 value to 0.18 with a decreased percentage level of $82.4 \%$, Aneka Guna Retail with a value of 1.07 to 0.71 with a percentage decrease of 33.6\%, Continent Retail with a value of 1.03 decreased to 0.86 with a percentage decrease of $16.5 \%$, and Retail Wayame which previously 1.10 value decreased to 0.96 with a decrease in the percentage rate of $12.7 \%$. Where the value of the bullwhip effect $>$ 1.01 can be interpreted that there is demand amplification, while the value of the bullwhip effect $<1.01$ can be interpreted that demand is still stable or there is a smoothing of the demand pattern. and product sales, and keep lead times stable.
\end{abstract}

Keywords: Supply Chain, Bullwhip Effect, Moving Average, Single exponential Smoothing, Mean Absolute Deviation, tracking signal 


\section{PENDAHULUAN}

Perkembangan industri didalam kota Ambon sampai saat ini menunjukan peningkatan yang cukup tinggi, hal ini di tandai dengan semakin banyaknya perusahaan-perusahaan yang baru berdiri baik yang merupakan investasi baru maupun perluasan dari perusahan yang telah ada.

Menurut Badan Pusat Statistik (BPS), 2017 tercatat pada dinas perdaganggan dan perindustrian kota Ambon, perusahaan/usaha industri selama tahun 2016 sebanyak 3.226 unit, dengan 7.681 tenaga kerja dan nilai investasi sebesar 89,72 milyar rupiah baik jumlah perusahaan maupun jumlah tenaga kerja meningkat masing-masing 76 dan 211 dari keadaan pada tahun 2015.

Pertumbuhan dalam suatu industri menggakibatkan semakin meningkatnya persainggan produk semen yang kompetitif dalam industri yang sejenis yaitu semen conch, semen tonasa, semen bosowa dan semen holcim. kebutuhan akan Permintaan semen di kota Ambon meningkat berdasarkan pembanggunan yang ada, menurut dinas tata kota pada tahun 2015 tercatat sebanyak 628 buah banggunan dimana 36 buah diperuntukan bagi banggunan kantor, 443 buah bagi banggunan tempat tinggal dan 149 buah untuk banggunan lainnya (BPS, 2017, p. 241).

Untuk bisa bertahan di tengah persaingan yang semakin ketat, hal utama yang harus diperhatikan oleh perusahaan adalah bagaimana memenuhi permintaan customer. Salah satu strategi yang dikembangkan dalam mewujudkan hal tersebut adalah strategi supply chain management. Salah satu permasalahan yang timbul pada supply chain adalah bullwhip effect. Bullwhip effect mendistorsi informasi permintaan dari mata rantai yang bawah (end customer) ke rantai di atasnya. Hal ini dikarenakan kesalahan dari interpertasi data permintaan ditiap-tiap rantai distribusi dan kesalahan informasi yang diterima. Kesalahan ini terjadi karena perbedaan jumlah permintaan yang diterima perusahan dengan jumlah yang dibutuhkan oleh pasar. Jumlah permiintaan yang diterima oleh perusahaan dari tiap-tiap retail berbeda dengan jumlah yang dibutuhkan oleh pasar atau konsumen kesalahan ini disebut bullwhip effect.

Distributor PT. Semen Tonasa, Distributor PT. Padi Mas Prima, Ritel Aneka Guna, Ritel Benua dan Ritel Wayame merupakan pelaku-pelaku dalam supply chain yang mendistribusikan produk semen merek tonasa, dalam penelitian tugas akhir ini yang akan dibahas adalah permasalahan yang terjadi pada rantai supply untuk produk semen merek Tonasa. Penelitian ini bertujuan untuk menganalisis bullwhip effect dengan metode peramalan pada produk semen tonasa dan memberikan alternatif yang tepat guna mengurangi bullwhip effect.

\section{LANDASAN TEORI}

\section{Konsep Supply Chain Management}

Supply chain adalah jaringan perusahaan-perusahaan yang secara bersama- sama bekerja untuk menciptakan dan menghantarkan suatu produk ke tangan pemakai akhir (dalam hal ini konsumen). Perusahaan-perusahaan tersebut biasanya termasuk supplier, pabrik, distributor, toko atau pengecer, serta perusahaan- perusahaan pendukung seperti perusahaan jasa logistik.

Informasi tentang persediaan produk yang masih ada di masing-masing supermarket sering dibutuhkan oleh distributor maupun pabrik. Informasi tentang ketersediaan kapasitas produksi yang dimiliki oleh supplier juga sering dibutuhkan oleh pabrik. Informasi tentang status pengiriman bahan baku sering dibutuhkan oleh perusahaan yang mengirim maupun yang akan menerima. Perusahaan pengapalan harus membagi informasi seperti ini supaya pihak-pihak yang berkepentingan dapat memonitor untuk kepentingan perencanaan yang lebih akurat.

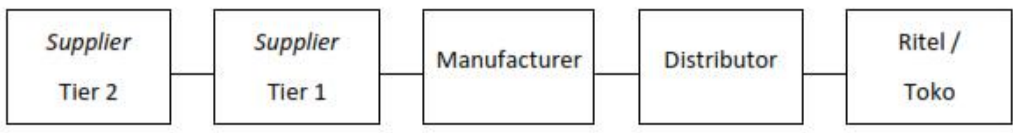

Aliran Supply Chain

supply chain management adalah serangkaian pendekatan yang digunakan untuk mengintegrasikan supplier secara efisien, manufaktur, gudang dan toko-toko, sehingga barang-barang dapat diproduksi dan didistribusikan dengan jumlah yang tepat, ke lokasi yang tepat, dan waktu yang tepat juga, dengan maksud menimimalkan keseluruhan sistem.

\section{Bullwhip Effect}

Distorsi informasi mengakibatkan pola permintaan yang semakin fluktuatif kearah hulu supply chain. Meningkatnya fluktuasi atau variabilitas permintaan dari hilir ke hulu suatu supply chain dinamakan bullwhi effect. Bullwhip effect merupakan istilah yang digunakan dalam dunia inventory 
yang mendefinisikan bagaimana pergerakan demand dalam supply chain. Bullwhip yaitu cambuk, alat untuk mengendalikan sapi atau banteng. Konsepnya adalah suatu keadaan yang terjadi dalam supply chain, dimana permintaan dari customer mengalami perubahan baik semakin banyak atau semakin sedikit, perubahan ini menyebabkan distorsi permintaan dari setiap stage supply chain. Distorsi tersebut menimbulkan efek bagi keseluruhan stage supply chain yaitu permintaan yang tidak akurat.

Bullwhip effect mengakibatkan banyak inefisiensi pada supply chain. Misalnya pabrik memproduksi dan mengirim lebih banyak dari yang sesungguhnya dibutuhkan akibat salah membaca signal permintaan dari pemain bagian hilir supply chain. Kegiatan dari pabrik dan pemasok lebih fluktuatif sehingga mereka sering lembur menghadapi pesanan yang berlebih atau menganggur karena distributor/ritel tidak memesan dalam waktu yang relatif panjang akibat mereka melakukan forward buying.

Bullwhip effect adalah suatu fenomena dimana satu lonjakan kecil di level konsumen akan mengakibatkan lonjakan yang sangat tajam di level yang jauh dari konsumen (Baihaqi). Ada banyak hal yang menyebabkan terjadinya bullwhip effect, diantaranya:

1. Forecast Demand

2. Order Batching

3. Price Fluctuation

4. Rationing And Shortage Gaming

\section{Peramalan}

Peramalan adalah perkiraan tingkat permintaan satu atau lebih produk selama beberapa periode mendatang (Hendra Kusuma, 2001, p. 13). Menurut Heizer \& Render (2015) Peramalan (forecfasting) adalah seni dan ilmu untuk memperkirakan kejadian masa depan. Hal ini dapat dilakukan dengan melibatkan pengambilan data masa lalu dan menempatkannya ke masa yang akan datang dengan suatu bentuk model matematis. Bisa juga merupakan prediksi intuisi yang bersifat subjektif . atau bisa juga dengan menggunakan model matematis yang disesuaikan dengan pertimbangan yang baik dari seorang manajer. Hanya sedikit bisnis yang dapat menghindari proses peramalan dan hanya menunggu apa yang terjadi untuk kemudian menggambil kesempatan. Perencanaan yang efektif baik untuk jangka panjang maupun jangka pendek bergantung pada peramalan permintaan untuk produk perusahaan tersebut. Peramalan adalah proses menggunakan pola-pola yang terkandung dalam data masa lampau untuk memprediksi nilai-nilai masa yang akan datang.

Menurut Yunarto (2005) kerangka waktu ramalan suatu perusahaan dengan perusahaan lain berbeda-beda tergantung pada jenis produk yang dipasarkan, namun umumnya kerangka waktu ramalan dibagi menjadi tiga kategori, yaitu:

1. Ramalan jangka pendek

Jangka waktu ramalan ini umumnya dibawah tiga bulan dan digunakan untuk perencanaan pembelian, penjadwalan produksi, dan penugasan.

2. Ramalan jangkah menengah

Jangka waktu ramalan ini lebih dari tiga tahun dan umumnya digunakan untuk perencanaan produk baru, perluasan pabrik, dan ekspansi pasar.

3. Ramalan jangkah panjang

Jangka waktu ramalan ini lebih dar tiga tahun dan umumnya digunakan untuk perencanaan produk baru, perluasan pabrik, dan ekspansi pasar

\section{Penentuan Pola Data}

Ploting data harus dilakukan sebelum melakukan metode peramalan untuk menentukan pola data yang terjadi. Dengan data yang ada diperoleh diagram pencarnya. Macam - macam dari plot data adalah sebagai berikut:

1. Konstan, adalah apabila pola data berfluktuasi di sekitar nilai rata - rata yang konstan (deret seperti ini stasioner terhadap nilai rata - ratanya).

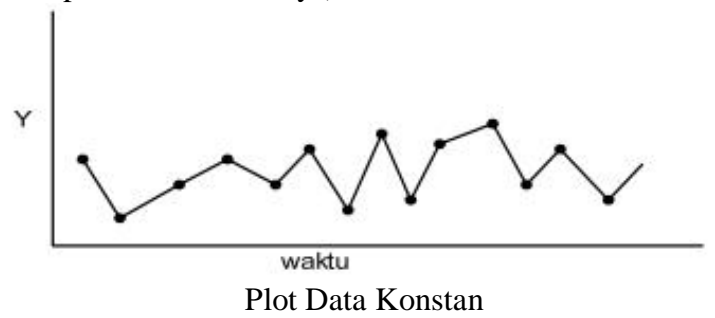


2. Linier/Trend, terjadi saat terdapat kenaikan dan penurunan jangka panjang dalam data

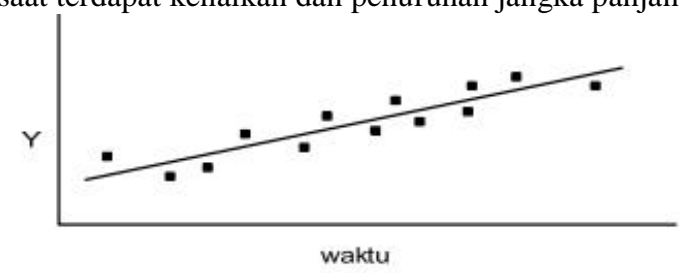

Plot Data Linier Atau Trend

3. Seasonal (Musiman), adalah fluktuasi permintaan suatu produk dapat naik turun di sekitar garis trend dan biasanya berulang tiap tahun.

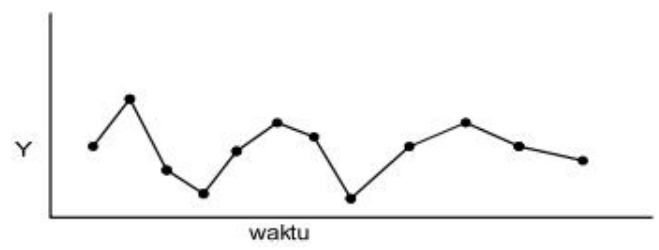

Plot Data Musiman

4. Cyclical (siklis), adalah pola permintaan suatu produkyang mempunyai siklus berulang secara periodik biasanya lebih dari satu tahun, sehingga pola ini untuk peramalan jangka menengah dan panjang.

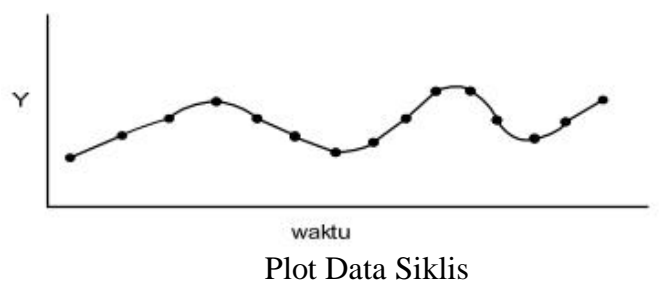

5. Random (acak), adalah tanda dalam data yang disebabkan peluang dan situasi yang tidak biasa, variabel acak mengikuti pola yang tidak dapat dilihat.

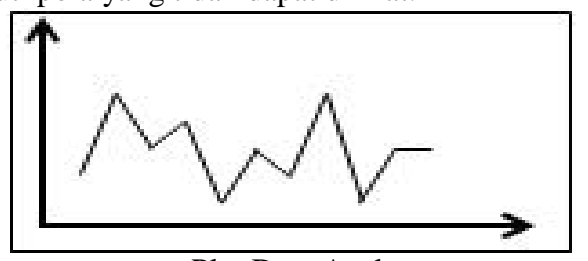

\section{Metode Peramalan}

Plot Data Acak

Metode peramalan adalah suatu cara memperkirakan secara kuantitatif apa yang akan terjadi di masa depan berdasarkan data-data relevan di masa lalu, maka peramalan ini digunakan dalam peramalan yang objektif.

1. Moving Average

Moving Average adalah metode peramalan perataan nilai dengan mengambil sekelompok nilai pengamaatan yang kemudian dicari rata-ratanya, lalu menggunaakan rata-rata tersebut sebagai ramlan untuk periode berikutnya. Metode ini akan efektif diterapkan apabila kita dapat mengasumsikan bahwa permintaan pasar terhadap produk akan tetap stabil sepanjang waktu. Berdasarkan horizon waktu, peramalan yang digunakan pada penelitian ini adalah ramalan jangka pendek yang dilakukan secara kontinyu untuk data penjualan, hal ini karena peramlan jangka pendek akan lebih akurat faktor-faktor yang mempengaruhi permintaan relatif masih konstan. Metode rata-rata bergerak menggunakan formula sebagai berikut:

$$
M A=\frac{\mathrm{At}+\mathrm{At}-1+\cdots+\mathrm{At}-(\mathrm{N}-1)}{\mathrm{N}}
$$

Dimana :

MA : Peramalan Penjualan

At : Penjualan Aktual Pada Periode T

N : Jumlah Data Penjualan Yang Dilibatkan Dalam Perhitungan MA. 
2. Exponential Smoothing

Peramalan pemulusan eksponensial bekerja hamper serupa dengan alat tremostart, dimana apabila galat ramalan (forecast error) adalah positif, yang berarti nilai aktual permintaan lebih tinggi dari pada nilai ramalan. Sebaliknya apabila galat ramalan ramalan (forecast error), adalah negative, yang berarti nilai actual permintaan lebih rendah dari pada nilai ramalan $(\mathrm{A}-\mathrm{f}<0)$, maka model pemulusan eksponensial akan secara otomatis menurunkan nilai ramalan. Proses penyusunan ini berlangsung terus menerus, kecuali galat ramalan telah mencapai nol. Kenyataan inilah yang mendorong peramal (forecaster) lebih suka menggunakan model peramalan pemulusan ekponensial, apabila pola historis dari data aktual permintaan bergejolak atau tidak stabil dari waktu. Penghalusan eksponensial merupakan metode peramalan rata-rata bergerak dengan pembobotan dimana titik data dibobotkan oleh fungsi eksponensial. Rumus penghalusan eksponensial:

Peramalan baru $=$ Peramalan periode terakhir + (permintaan sebenarnya periode terakhir peramalan periode terakhir)

$$
\text { Ft Ft-1 }+\alpha(\text { At-1 }- \text { Ft-1), }
$$

Ft : Peramalan baru

Ft-1 : Peramalan sebelumnya

A : Konstanta penghalusan (pembobotan, $0 \leq \alpha \quad \alpha \quad \leq 1)$

At-1 : Permintaan aktual periode lalu

3. Kesalahan Peramalan

Ketepatan ramalan adalah suatu hal yang mendasar dalam peramalan, yaitu bagaimana mengukur kesesuaian suatu metode peramalan tertentu untuk suatu kumpulan data yang diberikan.Ketepatan dipandang sebagai kriteria penolakan untuk memilih suatu metode peramalan. Dalam pemodelan deret berkala (time series) dari data masa laludapat diramalkan situasi yang akan terjadi pada masa yang akan datang, untuk menguji kebenaran ramalan ini digunakan ketepatan ramalan. Beberapa kriteria yang digunakan untuk menguji ketetpatan ramalan antara lain:

a. Mean Absolute Deviation

Mean Absolute Deviation (MAD) mengukur ketepatan ramalan dengan merata-rata kesalahan dugaan (Nilai absolut masing-masing kesalahan).

$$
M A D=\sum_{i=1}^{n} \frac{\left|x_{i}-\bar{x}\right|}{n}
$$

b. Mean Squared Error

Mean Squared Error (MSE) adalah metode lain untuk mengevaluasi metode peramalan. Masingmasing kesalahan atau sisa dikuadratkan. Kemudian dijumlahkan dan dibagi dengan jumlah observasi.

$$
M S F=\sum_{i=1}^{n} \frac{e_{i}^{2}}{n}
$$

c. Mean Absolute Percentage Error

Mean Absolute Percentage Error (MAPE) dihitung dengan menggunakan kesalahan absolut pada tiap periode dibagi dengan nilai observasi yang nyata untuk periode itu. Kemudian, merata- rata kesalahan persentase absolut tersebut.

$$
M A P E=\sum_{i=1}^{n} \frac{\left|P E_{i}\right|}{n}
$$

4. Tracking Signal

Tracking Signal adalah suatu ukuran bagaimana baiknya suatu ramalan memperkirakan nilai-nilai aktual suatu ramalan diperbaharui setiap minggu, bulan atau triwulan, sehingga data permintaan yang baru dibandingkan terhadap nilai-nilai ramalan. Tracking Signal dihitung sebagai running sum of the forecast errors dibagi dengan mean absolute deviation. Tracking signal yang positif menunjukan bahwa nilai aktual permintaan lebih besar daripada ramalan, sedangkan apabila negatif berarti nilai aktual permintaan lebih kecil daripada ramalan. Tracking signal terkadang digunakan untuk melihat apakah nilai-nilai yang dihasilkan berada didalam atau di luar batas-batas pengendalian. Rumus dari Tracking Signal adalah :

$$
\text { TRACKING SIGNAL }=\frac{R S F E}{M A D}
$$




\section{METODE PENELITIAN}

Variabel dan Definisi Operasional

Variabel keputusan dapat dinotasikan dengan lambang X. Yang termasuk dalam indikator variabel keputusan dalam penilitian adalah sebagai berikut :

a. Total Order Portland Composite Cement $\left(\mathrm{X}_{1}\right)$

b. Total Demand Portland Compocite Cement $\left(\mathrm{X}_{2}\right)$

Variabel keputusan merupakan suatu indikator untuk mencapai variabel tujuan. Yang mana variabel tujuan adalah Bullwhip Effect.

\section{Metode Analisa Data}

Adapun metode yang digunakan dalam menganalisis data-data yang diperoleh untuk mendapatkan perhitungan Bullwhip Effect guna menggurangi terjadinya Bullwhip Effect dalam supply chain dengan menggunakan metode peramalan.

Berikut ini merupakan flowchart dari penelitian ini.

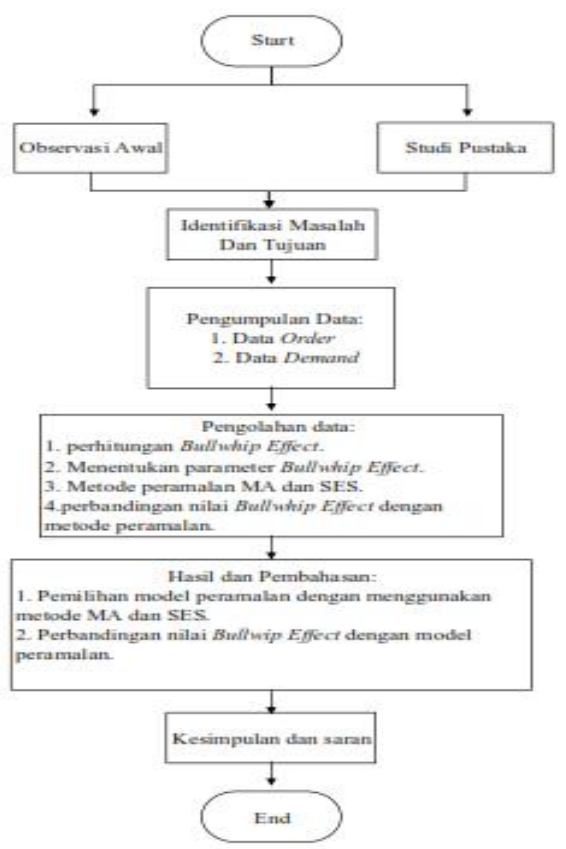

Flowchart Penelitian

HASIL DAN PEMBAHASAN

Berikut ini adalah gambar saluran distribusi PT. Semen Tonasa Ambon

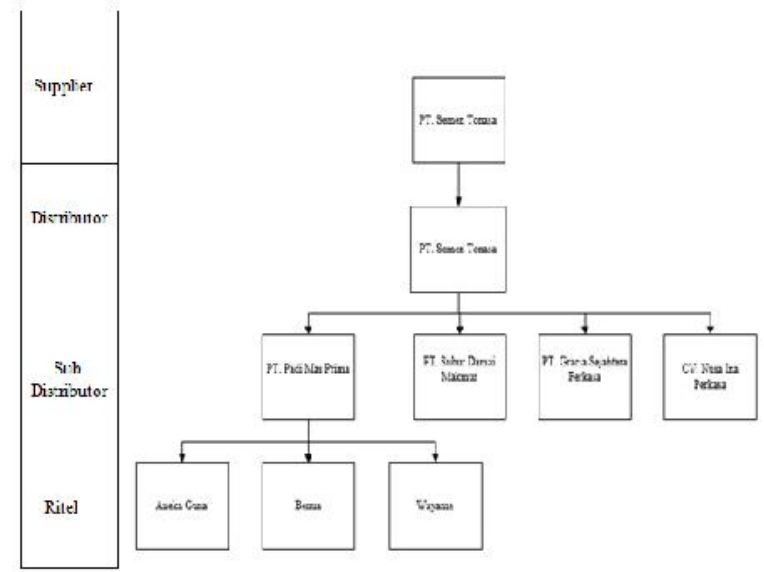

Saluran Distribusi PT. Semen Tonasa Ambon 
Perhitungan Nilai Bullwhip Effect Sub Distributor PT. Padi Mas Prima

Perhitungan Bullwhip Effect Pada Distributor PT. Padi Mas Prima

\begin{tabular}{|r|r|r|}
\hline \multicolumn{1}{|r|}{ Periode } & Order (O) & \multicolumn{1}{c|}{ Demand (D) } \\
\hline 1 & 20,225 & 19,940 \\
\hline 2 & 11,700 & 11,430 \\
\hline 3 & 33,911 & 33,520 \\
\hline 4 & 31,235 & 30,922 \\
\hline 5 & 45,080 & 44,925 \\
\hline 6 & 36,300 & 35,910 \\
\hline 7 & 37,975 & 37,892 \\
\hline 8 & 45,615 & 45,562 \\
\hline 9 & 44,460 & 44,421 \\
\hline 10 & 65,175 & 63,256 \\
\hline 11 & 52,200 & 49,899 \\
\hline 12 & 41,900 & 40,625 \\
\hline SUM & 465,776 & 458,302 \\
\hline AVERAGE & 38814.67 & 38191.83 \\
\hline SD & 14046.12 & 13614,65 \\
\hline CV & 0.362 & 0.36 \\
\hline BE & \multicolumn{2}{|c}{1.02} \\
\hline
\end{tabular}

Berdasarkan table diatas, perhitungan nilai BE terjadi amplifikasi atau kenaikan pemesanan dalam jumlah yang banyak dari sub distributor PT. Padi Mas Prima yang disebabkan, total pemesanan melebihi total penjualan pada Sub Distributor PT. Padi Mas Prima yaitu sebesar 465,776 sak > 458,302 sak, berdasarkan koefisien variansi order lebih besar dibandingkan dengan koefisien variansi demand dari distributor PT. Padi Mas Prima 0.362>0.36 yang mengakibatkan kenaikan BE yang cukup besar yaitu 1.02 dari sub distributor.

Perhitungan BE untuk ritel dari sub distributor adalah sebagai berikut:

A. Ritel Aneka Guna

Perhitungan Bullwhip Effect Pada Ritel Aneka Guna

\begin{tabular}{|r|r|r|}
\hline Perlode & Order (O) & \multicolumn{1}{|c|}{ Demand (D) } \\
\hline 1 & 400 & 360 \\
\hline 2 & 400 & 390 \\
\hline 3 & 400 & 350 \\
\hline 4 & 400 & 400 \\
\hline 5 & 400 & 400 \\
\hline 6 & 400 & 350 \\
\hline 7 & 400 & 360 \\
\hline 8 & 400 & 300 \\
\hline 9 & 600 & 550 \\
\hline 10 & 600 & 500 \\
\hline 11 & 600 & 450 \\
\hline 12 & 600 & 550 \\
\hline$S U M$ & 5,600 & 4,960 \\
\hline AVERAGE & 466.67 & 413.33 \\
\hline SD & 98.47 & 81.84 \\
\hline CV & 0.21 & 0.20 \\
\hline BE & & 1.07 \\
\hline
\end{tabular}

B. Ritel Benua

Perhitungan Bullwhip Effect Pada Ritel Aneka Guna

\begin{tabular}{|r|r|r|}
\hline \multicolumn{1}{|c|}{ Periode } & \multicolumn{1}{|c|}{ Order (O) } & \multicolumn{1}{c|}{ Demand (D) } \\
\hline 1 & 10,000 & 8,600 \\
\hline 2 & 8,000 & 7,800 \\
\hline 3 & 8,000 & 7,200 \\
\hline 4 & 8,000 & 6,500 \\
\hline 5 & 8,000 & 7,800 \\
\hline 6 & 10,000 & 9,200 \\
\hline 7 & 10,000 & 8,400 \\
\hline 8 & 10,000 & 9,000 \\
\hline 9 & 10,000 & 8,600 \\
\hline 10 & 10,000 & 9,000 \\
\hline 11 & 10,000 & 9,200 \\
\hline 12 & 10,000 & 8,800 \\
\hline SUM & 112,000 & 100,100 \\
\hline AVERAGE & 9333.33 & 8341.67 \\
\hline$S D$ & 984.73 & 851.16 \\
\hline$C V$ & 0.11 & 0.10 \\
\hline BE & & 1.03 \\
\hline
\end{tabular}


C. Ritel Wayame

Perhitungan Bullwhip Effect Pada Rite
\begin{tabular}{|r|r|r|}
\hline Perlode & Order $(\mathbf{O})$ & Demand (D) \\
\hline 1 & 250 & 210 \\
\hline 2 & 250 & 200 \\
\hline 3 & 250 & 230 \\
\hline 4 & 250 & 240 \\
\hline 5 & 500 & 400 \\
\hline 6 & 500 & 420 \\
\hline 7 & 500 & 400 \\
\hline 8 & 500 & 450 \\
\hline 9 & 250 & 250 \\
\hline 10 & 250 & 250 \\
\hline 11 & 250 & 190 \\
\hline 12 & 250 & 230 \\
\hline$S U M$ & 4,000 & 3,470 \\
\hline$A V E R A G E$ & 333.33 & 289.17 \\
\hline$S D$ & 123.09 & 97.28 \\
\hline$C V$ & 0.37 & 0.34 \\
\hline$B E$ & & 1.10 \\
\hline
\end{tabular}

\section{Parameter Bullwhip Effect}

Pada perhitungan BE di atas, maka dibuat parameter untuk dapat membandingkan apakah terjadi BE dan jika nilai BE lebih besar dari parameter yang ditetapkan maka perlu adanya penekanan bullwhip effect. Adapun perhitunganya sebagai berikut:

Lead time $(\mathrm{L})=1$ hari

Periode pengamatan $(\mathrm{P})=12$ bulan $/ 360$ hari

Parameter bullwhip effect (BE) :

$$
1+\frac{2 \times 1}{360}+\frac{2 \times 1^{2}}{360^{2}}=1,01
$$

Perbandingan Parameter Bullwhip Effect

\begin{tabular}{|l|r|c|}
\hline $\begin{array}{l}\text { Sub Distributor dan } \\
\text { Ritel (2017) }\end{array}$ & Nillai BE & Parameter BE \\
\hline PT. Padi Mas Prima & 1,02 & \multirow{2}{*}{1,01} \\
\hline Aneka Guna & 1,07 & \multirow{2}{*}{1,03} \\
\cline { 1 - 2 } Benua & 1,10 & \\
\hline Wayame & \multicolumn{2}{|l|}{} \\
\hline
\end{tabular}

Dari tabel diatas dapat dijelaskan bahwa hasil perbandingan Nilai BE tersebut, didapatkan dari sub distributor dan ritel tahun 2017 dari PT. Padi Mas Prima, Ritel Aneka Guna, Ritel Benua dan Ritel Wayame. Nilai BE berada di atas parameter sebesar 1,01. Pada distributor PT. Padi Mas Prima nilai BE sebesar 1,02. Pada Ritel Aneka Guna nilai BE sebesar 1.07, pada Ritel Benua nilai BE sebesar 1.03 sedangkan pada Ritel Wayame nilai BE sebesar 1.10. Pihak distributor dan ritel perlu melakukan penanganan yang secara intensif dan berkala untuk menekan peningkatan nilai BE pada tahun-tahun selanjutnya agar nilai bullwhip effect tidak semakin besar.

\section{Peramalan}

Peramalan atau forecast adalah suatu fungsi bisnis yang berusaha memperkirakan penjualan dan penggunaan produk sehingga produk-produk itu dapat dibuat dalam kuantitas yang tetap (Gaspersz, 1998). Beberapa indikator digunakan dalam pengukuran akurasi peramalan yang umum digunakan adalah MAD (Mean Absolute Deviation), MAPE (Mean Absolute Preceetage Error) dan MSE (Mean Square Error). Akurasi peramalan akan semakin baik apabila nilai-nilai MAD,MAPE dan MSE semakin kecil. Peramalan akan dilihat berdasarkan tingkat penjualan semen tonasa pada tahun 2017 di Distributor PT. Padi Mas Prima, Ritel Aneka Guna, Ritel Benua dan Ritel Wayame berdasarkan data historis Demand Semen Tonasa selama 12 bulan terakhir sebagai berikut: 
Distributor PT. Padi Mas Prima

Total Demand Distributor PT. Padi Mas Prima

\begin{tabular}{|r|r|r|}
\hline NO & \multicolumn{1}{|c|}{ Month } & \multicolumn{1}{c|}{ Demand } \\
\hline 1 & Januari & 19,940 \\
\hline 2 & Febuari & 11,430 \\
\hline 3 & Maret & 33,520 \\
\hline 4 & April & 30,922 \\
\hline 5 & Mei & 44,925 \\
\hline 6 & Juni & 35,910 \\
\hline 7 & Juli & 37,892 \\
\hline 8 & Agustus & 45,562 \\
\hline 9 & September & 44,421 \\
\hline 10 & Oktober & 63,256 \\
\hline 11 & November & 49,899 \\
\hline 12 & Desember & 40,625 \\
\hline \multicolumn{3}{|c|}{ Total } \\
\hline
\end{tabular}

Total penjualan untuk ritel dari sub distributor sebagai berikut:

1. Ritel Guna Aneka

Total Demand Pada Ritel Aneka Guna

\begin{tabular}{|r|c|r|}
\hline No & Month & \multicolumn{2}{|c|}{ Demand } \\
\hline 1 & Januari & 360 \\
\hline 2 & Febuari & 390 \\
\hline 3 & Maret & 350 \\
\hline 4 & April & 400 \\
\hline 5 & Mei & 400 \\
\hline 6 & Juni & 350 \\
\hline 7 & Juli & 360 \\
\hline 8 & Agustus & 300 \\
\hline 9 & September & 550 \\
\hline 10 & Oktober & 500 \\
\hline 11 & November & 450 \\
\hline 12 & Desember & 550 \\
\hline \multicolumn{2}{|c}{ Total } & 4,960 \\
\hline
\end{tabular}

2. Ritel Benua

Total Demand Pada Ritel Benua

\begin{tabular}{|r|c|r|}
\hline \multicolumn{1}{|c|}{ No } & Month & \multicolumn{2}{|c|}{ Demand } \\
\hline 1 & Januari & 8,600 \\
\hline 2 & Febuari & 7,800 \\
\hline 3 & Maret & 7,200 \\
\hline 4 & April & 6,500 \\
\hline 5 & Mei & 7,800 \\
\hline 6 & Juni & 9,200 \\
\hline 7 & Juli & 8,400 \\
\hline 8 & Agustus & 9,000 \\
\hline 9 & September & 8,600 \\
\hline 10 & Oktober & 9,000 \\
\hline 11 & November & 9,200 \\
\hline 12 & Desember & 8,800 \\
\hline & Total & 100,100 \\
\hline
\end{tabular}

3. Ritel Wayame

Total Demand Pada Ritel Wayame

\begin{tabular}{|r|c|r|}
\hline \multicolumn{1}{|c|}{ No } & Month & \multicolumn{2}{|c|}{ Demand } \\
\hline 1 & Januari & 210 \\
\hline 2 & Febuari & 200 \\
\hline 3 & Maret & 230 \\
\hline 4 & April & 240 \\
\hline 5 & Mei & 400 \\
\hline 6 & Juni & 420 \\
\hline 7 & Juli & 400 \\
\hline 8 & Agustus & 450 \\
\hline 9 & september & 250 \\
\hline 10 & Oktober & 250 \\
\hline 11 & november & 190 \\
\hline 12 & desember & 230 \\
\hline & Total & 3,470 \\
\hline
\end{tabular}




\section{Ploting Data Aktual Penjualan Semen Tonasa}

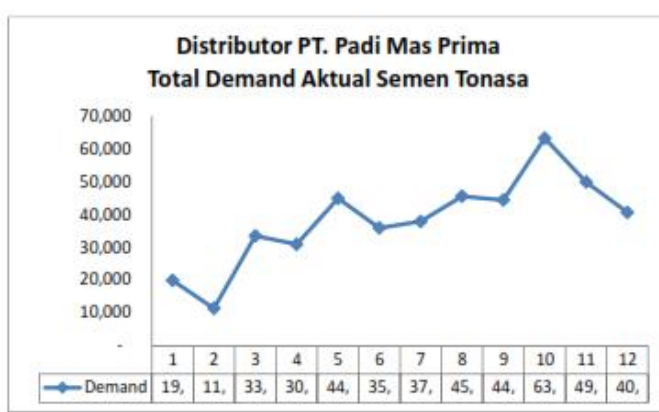

Plot data Total Demand Aktual Semen Tonasa Sub Distributor PT. Padi Mas Prima

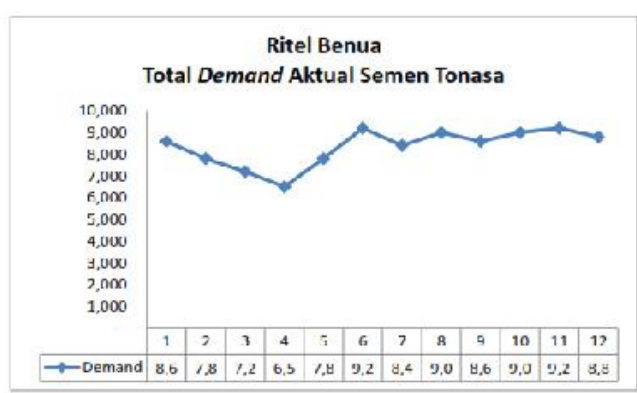

Plot Data Total Demand Aktual Semen Tonasa Ritel Benua

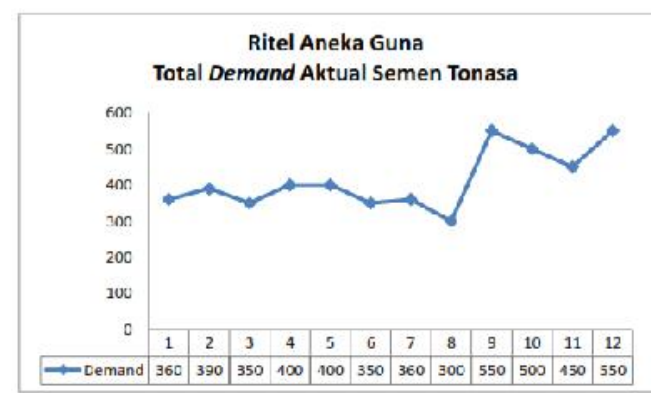

Plot Data Total Demand Aktual Semen Tonasa Ritel Aneka Guna

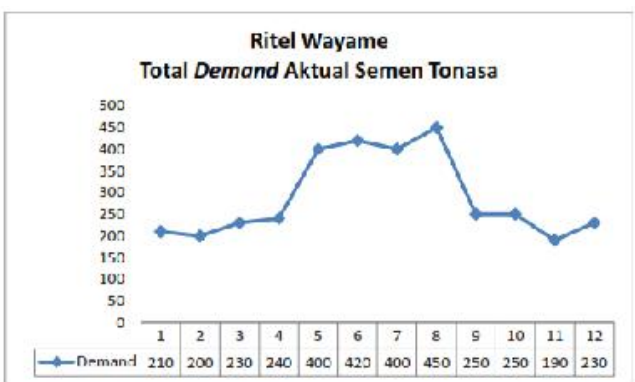

Plot Data Total Demand Aktual Semen Tonasa Ritel Wayame

Peramalan Moving Average Dan Single Exponential Smoothing

Nilai MAPE Dan MAD Untuk MA Dan SES Penjualan Sub Distributor PT. Padi Mas Prima dengan software Minitab

\begin{tabular}{|r|r|r|}
\hline \multicolumn{1}{|c|}{ MA } & \multicolumn{1}{|c|}{ MAPE } & \multicolumn{1}{c|}{ MAD } \\
\hline 1 & 28 & 9861 \\
\hline 2 & 22 & 9304 \\
\hline 3 & 18 & 8271 \\
\hline 4 & 20 & 9292 \\
\hline 5 & 19 & 8887 \\
\hline 6 & 21 & 10217 \\
\hline 7 & 24 & 12249 \\
\hline 8 & 24 & 12728 \\
\hline 9 & 25 & 14323 \\
\hline 10 & 14 & 6986 \\
\hline 11 & 7 & 2654 \\
\hline
\end{tabular}

\begin{tabular}{|r|r|r|}
\hline \multicolumn{1}{|c|}{ SES } & \multicolumn{1}{|c|}{ MAPE } & \multicolumn{1}{c|}{ MAD } \\
\hline$\alpha 0,25$ & 38 & 9998 \\
\hline$\alpha 0,20$ & 38 & 9946 \\
\hline$\alpha 0,15$ & 38 & 9916 \\
\hline$\alpha 0,10$ & 38 & 9786 \\
\hline$\alpha 0,05$ & 40 & 9958 \\
\hline$\alpha 0,01$ & 40 & 9941 \\
\hline
\end{tabular}

Perhitungan Moving Average dan Single Exponential Smoothing Untuk Ritel dari sub distributor sebagai berikut: 
1. Ritel Aneka Guna

Nilai MAPE Dan MAD Untuk MA Dan SES Penjualan Ritel Aneka Guna dengan software Minitab

\begin{tabular}{|r|r|r|}
\hline \multicolumn{1}{|l|}{ MA } & \multicolumn{1}{l|}{ MAPE } & \multicolumn{1}{l|}{ MAD } \\
\hline 1 & 13.95 & 62.73 \\
\hline 2 & 14.3 & 64.5 \\
\hline 3 & 13.32 & 60 \\
\hline 4 & 15.92 & 72.81 \\
\hline 5 & 17.61 & 81.71 \\
\hline 6 & 19.6 & 93.1 \\
\hline 7 & 22.8 & 109.4 \\
\hline 8 & 23 & 120.9 \\
\hline 9 & 20.1 & 103 \\
\hline 10 & 19.2 & 99.5 \\
\hline 11 & 27.1 & 149.1 \\
\hline
\end{tabular}

\begin{tabular}{|c|r|c|}
\hline \multicolumn{1}{|c|}{ SES } & MAPE & \multicolumn{1}{c|}{ MAD } \\
\hline$\alpha 0,99$ & 33 & 10519 \\
\hline$\alpha 0,95$ & 33 & 10353 \\
\hline$\alpha 0,90$ & 33 & 10148 \\
\hline$\alpha 0,85$ & 33 & 10030 \\
\hline$\alpha 0,80$ & 34 & 10042 \\
\hline$\alpha 0,75$ & 34 & 10042 \\
\hline
\end{tabular}

2. Ritel Benua

Nilai MAPE Dan MAD Untuk MA Dan SES Penjualan Ritel Benua dengan software Minitab

\begin{tabular}{|r|r|r|}
\hline \multicolumn{1}{|c|}{ MA } & MAPE & MAD \\
\hline 1 & 8 & 691 \\
\hline 2 & 8 & 630 \\
\hline 3 & 8 & 689 \\
\hline 4 & 7 & 588 \\
\hline 5 & 8 & 674 \\
\hline 6 & 7 & 617 \\
\hline 7 & 8 & 697 \\
\hline 8 & 8 & 700 \\
\hline 9 & 9 & 796 \\
\hline 10 & 8 & 760 \\
\hline 11 & 6 & 500 \\
\hline
\end{tabular}

\begin{tabular}{|c|r|r|}
\hline \multicolumn{1}{|l|}{ SES } & MAPE & \multicolumn{1}{c|}{ MAD } \\
\hline$\alpha 0,99$ & 8 & 654 \\
\hline$\alpha 0,95$ & 8 & 650 \\
\hline$\alpha 0,90$ & 8 & 644 \\
\hline$\alpha 0,85$ & 8 & 639 \\
\hline$\alpha 0,80$ & 8 & 633 \\
\hline$\alpha 0,75$ & 8 & 627 \\
\hline
\end{tabular}


3. Ritel Wayame

Nilai MAPE Dan MAD Untuk MA Dan SES Penjualan Ritel Wayame dengan software Minitab

\begin{tabular}{|r|r|r|}
\hline \multicolumn{1}{|c|}{ MA } & MAPE & \multicolumn{1}{c|}{ MAD } \\
\hline 1 & 19.28 & 54.55 \\
\hline 2 & 24.37 & 71 \\
\hline 3 & 32.2 & 93.3 \\
\hline 4 & 42.5 & 124.4 \\
\hline 5 & 45.2 & 126.6 \\
\hline 6 & 46.4 & 122.8 \\
\hline 7 & 46.3 & 117.4 \\
\hline 8 & 43 & 94.38 \\
\hline 9 & 42.41 & 90.37 \\
\hline 10 & 46.13 & 94 \\
\hline 11 & 28.06 & 64.55 \\
\hline
\end{tabular}

\begin{tabular}{|r|r|r|}
\hline \multicolumn{1}{|c|}{ SES } & MAPE & \multicolumn{1}{c|}{ MAD } \\
\hline$\alpha 0,99$ & 20.91 & 56.86 \\
\hline$\alpha 0,95$ & 21.29 & 57.92 \\
\hline$\alpha 0,90$ & 21.77 & 59.23 \\
\hline$\alpha 0,85$ & 22.24 & 60.5 \\
\hline$\alpha 0,80$ & 22.71 & 61.71 \\
\hline$\alpha 0,75$ & 23.14 & 62.85 \\
\hline
\end{tabular}

Dari hasil peramalan diatas metode yang dipilih adalah metode SES yang memberikan nilai erro terkecil.

\section{Perbandingan Nilai Bullwhip Effect}

\begin{tabular}{|c|r|r|}
\hline $\begin{array}{c}\text { Sub Distributor dan } \\
\text { Ritel }\end{array}$ & $\begin{array}{c}\text { BE (Sebelum } \\
\text { Peramalan) }\end{array}$ & $\begin{array}{c}\text { BE (Sesudah } \\
\text { Peramalan SES ) }\end{array}$ \\
\hline PT. Padi Mas Prima & 1.02 & 0.18 \\
\hline Aneka Guna & 1.07 & 0.71 \\
\hline Benua & 1.03 & 0.86 \\
\hline Wayame & 1.10 & 0.96 \\
\hline
\end{tabular}

Berdasarkan tabel di atas, perbandingan hasil perhitungan bullwhip effect sebelum diterapkan model peramalan dan sesudah diterapkan model peramalan Single exponential smoothing yang telah dipilih didapatkan hasil bahwa terjadi penurunan nilai BE. Pada distributor PT. Padi Mas Prima terjadi penurunan BE atau ketidakpastian permintaan konsumen menurun dari peramalan yang digunakan dimana sebelumnya 1.02 nilainya menjadi 0.18 dengan tingkat presentase penurunan sebesar $82.4 \%$, Ritel Aneka Guna yang nilainya 1.07 menjadi 0.71 dengan tingkat presentase penurunan sebesar 33.6\%, Ritel Benua yang nilainya 1.03 nilainya menurun menjadi 0.86 dengan tingkat presentase penurunan sebesar $16.5 \%$, dan Ritel Wayame yang sebelumnya 1.10 nilainya menurun menjadi 0.96 dengan tingkat presentase penurunan sebesar $12.7 \%$. bisa diartikan bahwa penerapan model peramalan dengan pemilihan model Single Exponential Smoothing pada sub distributor dan ritel tersebut merupakan salah satu pendekatan yang bisa diterapkan untuk menekan terjadinya bullwhip effect. Dengan berkurangnya Bullwhip Effect maka perusahaan akan memperoleh keuntungan sebagai berikut Argiyantari, M.M. (2014) dan Zaroni, CISCP. (2015):

1. Kepastian pemesanan lebih terencana.

2. Sharing informasi disepanjang rantai pasok lebih baik.

3. Tingkat persediaanya lebih diketahui.

4. Penciptaan tim rantai pasok lebih teratur.

5. Kinerja setiap rantai pasok bisa diukur.

6. Bisa terbangun kordinasi dan kolaborasi diantara mitra bisnis sehingga proses penggiriman produk dari pemasok ke perusahaan dan konsumen dapat berjalan dengan lancar.

Dengan adanya sistem peramalan yang tepat maka Sub Distributor PT. Padi Mas Prima, Ritel Aneka Guna, Ritel Benua dan Ritel Wayame perlu memperbaiki terjadinya BE. Untuk itu upaya yang harus dilakukan oleh Sub Distributor dan Ritel adalah sebagai berikut:

1. Untuk melakukan pemesanan produk Semen Tonasa oleh Sub Distributor PT. Padi Mas Prima pada Distributor PT. Semen Tonasa harus memperhatikan jumlah persediaan yang ada dengan memperhatikan tingkat penjualan sehingga jumlah Order tidak lebih besar dari Demand. Begitu juga sebaliknya pemesanan yang dilakukan oleh Ritel ke Sub Distributor PT. Padi Mas Prima 
2. Dalam mengantisipasi terjadinya kenaikan Order harus memperhatikan persediaan barang yang ada digudang, sehingga dapat mengantisipasi kenaikan Demand baik itu di Sub Distributor PT. Padi Mas Prima maupun Ritel.

3. Perlu adanya koordinasi antara pihak Distributor PT. Semen Tonasa, Sub Distributor PT. Padi Mas Prima dan Ritel haruslah ditingkatkan, agar aliran informasi mengenai permintaan pasar segera diketahui.

4. Perlu melakukan konfirmasi kepada pihak Distributor PT. Semen Tonasa oleh Sub Distributor PT. Padi Mas Prima dan sebaliknya dari Ritel ke Sub Distributor PT. Padi Mas Prima apabila terjadi peningkatan Order agar arus informasi tidak mengalami penundaan sehingga arus informasi Order produk Semen Tonasa menjadi lancar.

5. Tetap menjaga Lead Time agar tetap stabil dengan melakukan Order ke Distributor PT. Semen Tonasa dan Sub Distributor PT. Padi Mas Prima sesuai dengan tingkat kebutuhan, Sehingga tidak ada $O r d e r$ yang berlebihan

\section{KESIMPULAN}

berikut :

Berdasarkan hasil penelitian maka kesimpulan yang diperoleh dari hasi pembahasan adalah sebagai

1. Berdasarkan hasil perhitungan pada produk Semen Tonasa dapat diketahui terjadinya Bullwhip Effect pada Sub Distributor PT. Padi Mas Prima dengan nilai BE 1.02, Ritel Aneka Guna dengan nilai BE 1.07, Ritel Benua dengan nilai BE 1.03, Ritel Wayame dengan nilai BE 1.10, nilai BE tersebut di atas parameter yaitu 1.01. Perbaikan yang dilakukan dengan pemilihan metode peramalan dengan Moving Average dan Single Exponential Smoothing, pemilihan peramalan yang dipilih untuk Sub Distributor dan Ritel adalah metode Single Exponential Smoothing, dari Sub distributor PT. Padi Mas Prima SES $\alpha=0.10$, Ritel Aneka Guna SES $\alpha=0.75$, Ritel Benua SES $\alpha=0.75$, Ritel Wayame SES $\alpha=0.99$, dengan pemilihan metode peramalan dan perhitungan kembali nilai Bullwhip Effect untuk produk Semen Tonasa didapatkan hasil untuk Sub Distributor PT. Padi Mas Prima dengan nilai BE 0.18 dengan tingkat presentase penurunan sebesar 82.4\%, Ritel Aneka Guna dengan nilai BE 0.61 dengan tingkat presentase penurunan sebesar 33.6\%, Ritel Benua dengan nilai BE 0.86 dengan tingkat presentase penurunan sebesar 16.5\%, Ritel Wayame dengan nilai BE 0.96 dengan tingkat presentase penurunan sebesar $12.7 \%$, nlai BE tersebut dibawah parameter 1.01.

2. Usaha dalam memperbaiki bullwhip Effect diantaranya dalam melakukan pemesanan produk Semen Tonasa oleh Sub Distributor dan distributor perlu memperhatikan tingkat penjualan agar jumlah Order tidak lebih besar dari Demand Begitu juga sebaliknya pemesanan yang dilakukan oleh Ritel ke Sub Distributor PT. Padi Mas Prima, menjaga arus informasi Order dan Demand produk Semen Tonasa, serta tetap menjaga Lead Time agar tetap stabil.

\section{DAFTAR PUSTAKA}

Ambon, B. P. S. (2017). Kota Ambon dalam angka 2017. Badan Pusat Statistik Maluku, Ambon.

Argiyantari, M.M. (2014). Meningkatkan Daya Saing Perusahaan melalui Kolaborasi Retrieved from http://supplychainindonesia.com/new/meningkatkan-daya-saing-perusahaan- melalui-kolaborasisupplier/

Arina, F, E., Ade. \& Lukmandono (2015). Penerapan Metode Model Autoregressive Integrated Moving Average Guna Mengurangi Terjadinya Bullwhip Effect Pada Supply Chain, 111-116.

Asmono, T, F. (2012). Analisa Bullwhip Effect Pada Retail Air Minum Dalam Kemasan.

Barung, M. Marcelinus. (2011). Pengurangan Bullwhip Effect pada Rantai Pasok di Level Distributor Y. Program Studi Teknik Industri. Universitas Hasanuddin Makasar.

Bernard, W. T., III. (2005). Introduction to Management Science (Sains Manajemen) Edisi 8, Penerbit Salemba Empat, Jakarta.

Fransoo, J. C., \& Wouters, M. J. F. (2000). Measuring the bullwhip effect in the supply chain. Supply Chain Management: An International Journal. https://doi.org/10.1108/13598540010319993

Heizer, J. \& Barry, R. (2015), Operations Management (Manajemen Operasi), ed.11, Penerjemah: Dwi anoegrah wati S dan Indra Almahdy, Salemba empat, Jakarta.

Kusuma, Hendra. (2001). Perencanaan dan Pengendalian Produksi. Edisi Pertama. Andi Offset. Yogyakarta. 
